\title{
Mujeres en la toma de la Cervecería Córdoba. Experiencia de resistencia al neoliberalismo en los noventa
}

Fátima Boccetti*

Cuadernos de Historia. Serie economía y sociedad, N²6/27, 2021, pp. 171 a 197.

RECIBIDO: 31/08/2020. EVALUADO: 29/03/2021. ACEPTADO: 19/04/2021.

\section{Resumen}

El siguiente trabajo pretende una aproximación a la experiencia femenina durante el recrudecimiento neoliberal en Córdoba hacía finales de la década del noventa. A partir de la historia reciente y la historia oral, mediante el testimonio de una de las mujeres que luchó junto a los trabajadores de la Cervecería Córdoba, busca entender desde una perspectiva de género a las acciones colectivas en clave de politización y repolitización de las mujeres que desarrollaron sus prácticas y acciones en los márgenes del circuito doméstico en un contexto fuertemente convulsionado, cuyo objetivo no residía sólo en expresarse sino transformar la realidad.

Palabras clave: Neoliberalismo - Mujeres - Cervecería Córdoba.

\section{Summary}

The following work pretends an approach to the female experience during the neoliberal upsurge in Córdoba at the end of the 90s. From recent history, through the testimony of one of the women who struggled alongside the workers of Cervecería Córdoba, trying to understand from a gender perspective the collective actions in politicization and re-politicization of women who developed their practices and actions far away from the domestic environment, in a highly convulsed context, whose objective was not only to express themselves but transform reality.

Keywords: Neoliberalism - Women - Cervecería Córdoba

* Universidad Nacional de Córdoba. E mail: fatimaboccetti@gmail.com 


\section{Introducción}

El 17 de agosto de 1998 se conmemoraba en Córdoba un año más del fallecimiento del General José de San Martin, aquel día la celebración en la plaza principal de la ciudad se tiñó de luchas, resistencias y violencias. La mañana cordobesa amaneció con la noticia del desalojo de los trabajadores de la Cervecería Córdoba, quienes esa madrugada junto a sus familias y vecinos, vieron como las políticas económicas del neoliberalismo les arrebataban sus puestos de trabajo, tras ciento cinco días de lucha ocupando el establecimiento fabril. Ante eso, los obreros acompañados de sus esposas, madres, hijas y hermanas ocuparon la plaza para reclamar una vez más por su fuente de trabajo.

El conflicto de la Cervecería Córdoba fue uno de los más significativos del período que comprende la década del noventa debido a que fue considerado por la prensa local como la toma más larga de la historia obrera cordobesa y significó, según sus protagonistas, un hecho trascendental que contó con la unión obrero estudiantil para poner en jaque a las políticas del gobierno local.

Hacia finales de la década anterior asumía la presidencia del país Carlos Saúl Menem y con él se gestaban un conjunto de reformas que tendrían un fuerte impacto social. La aplicación de las políticas neoliberales en el país conllevó a una fuerte desregulación económica y a una reestructuración global del Estado, acentuando las desigualdades existentes y generando nuevos procesos de exclusión. Este proceso de reestructuración "supuso la aplicación de políticas de ajuste y de reforma en los espacios provinciales; Córdoba no sería ajena y el impacto de estas medidas causaría múltiples reacciones" sobre todo tras la asunción prematura del gobernador Ramón Bautista Mestre, cuyo gobierno significó una transición hacia la desarticulación del Estado de bienestar y de su reorganización bajo postulados neoliberales en la provincia.

La Argentina neoliberal se vio convulsionada por la existencia de permanentes conflictos motivados por la implementación de las políticas económicas del modelo. Aparecía allí la emergencia de nuevas formas de resistencia y militancia reflejadas en

1 Gordillo, 2012:12. 
"repertorios de lucha asociados a la acción directa y a nuevos formatos organizativos". ${ }^{2}$ Para analizar estas prácticas, Barrancos sostiene que la sustentabilidad de los procesos de lucha reposa en gran medida sobre los cuerpos femeninos. ${ }^{3} \mathrm{Al}$ respecto, Andújar considera que las mujeres hacen su aparición cuando se presentan escenarios históricos en los que las crisis sociales se agudizan, ya que el impacto de tal crisis en la organización de la vida cotidiana es genéricamente diferencial y somete a las mujeres a un plus de frustración y violencia social que generalmente escapa a los varones. ${ }^{4}$

Históricamente se ha instalado que las mujeres cumplen funciones en el ámbito de lo privado, esperando de ellas actitudes ligadas a la sumisión, los afectos, la maternidad, la pasividad. Por tal motivo Lipovesky plantea la necesidad de interrogarse sobre el lugar de las mujeres y sus acciones colectivas en el ámbito de lo público. ${ }^{5}$ Es por ello, que aquí se busca establecer una primera aproximación ${ }^{6}$ a la experiencia de las mujeres durante el recrudecimiento neoliberal en Córdoba, desde la historia reciente, y una fase exploratoria sobre la historia oral a partir del testimonio de una de las mujeres que luchó junto a los trabajadores de la Cervecería Córdoba durante el desarrollo del conflicto en la segunda mitad de la década del noventa. Se espera con este trabajo analizar la participación de las mujeres en el conflicto cervecero como una forma de organización colectiva en la que se indagan las modalidades y se las observa como protagonistas activas en el proceso de toma de los espacios, emergiendo como sujetos políticos con nuevas formas para hacer, ser y decir en el espacio público. Para ello, será necesario establecer algunas consideraciones que delineen las condiciones sociopolíticas de los noventa a nivel nacional y provincial para finalmente, tras poner en conocimiento en qué consistió el conflicto de la Cervecería Córdoba, poder entender desde una perspectiva de género y a través de la historia oral, que estas

2 Svampa, 2005: 201.

3 Barrancos, 2012.

4 Andújar, 2007.

5 Lipovesky, 1996.

6 La investigación es el inicio de un largo camino que busca culminar en el trabajo final de la Licenciatura en Historia, que se ha ido nutriendo a raíz del cursado de seminarios dictados en la Escuela de Historia de la Facultad de Filosofía y Humanidades de la Universidad Nacional de Córdoba, como así también de experiencias propias producto de un recorrido en tanto integrante del Proyecto SeCyT "Militancias, Dictaduras y Derechos Humanos en la Historia Reciente de Córdoba" acreditado por la Facultad de Filosofía y Humanidades, Secretaría de Ciencia y Técnica de la Universidad Nacional de Córdoba, en el marco de Programas de Incentivos del Ministerio de Educación de la Nación. 
acciones colectivas pueden ser analizadas en clave de politización y repolitización de las mujeres, quienes desarrollaron sus prácticas y acciones en los márgenes del circuito doméstico en un contexto fuertemente convulsionado.

\section{Las políticas neoliberales de los años noventa en Argentina}

Tras la asunción en el ejecutivo nacional de Carlos Saúl Menem, el 8 de julio de 1989, se buscó solucionar los problemas de crisis fiscal y de credibilidad política que se venían gestando desde años anteriores. Para ello llevó a cabo una serie de medidas de estabilización económica y política de cambio estructural, que comenzarían luego a perfilarse con la aprobación de dos leyes importantes que redefinirían el papel del Estado y las reglas del juego económico, social y político: la Ley de Emergencia Económica $^{7}$ y la Ley de Reforma del Estado, ${ }^{8}$ siendo esta última ley el pilar de la política de privatizaciones que convirtió a las mismas en una de las políticas centrales del gobierno de aquel entonces. ${ }^{9}$ La primera ley modificaba los sistemas de protección industrial y desregulaba la economía; la segunda, por su parte, habilitaba políticas de ajuste, de reestructuración, descentralización y privatización de empresas estatales nacionales.

Sin dudas la base para la consolidación de la nueva orientación económica fue el conjunto de medidas adoptadas desde abril de 1991, a partir de la llegada de Domingo Cavallo al ministerio de economía. La Ley de Convertibilidad ${ }^{10}$ que establecía la paridad fija del peso argentino con el dólar, permitió poner fin al problema de la inflación y atrajo la inversión extranjera.

Sin embargo, más allá de todas aquellas implementaciones, el modelo neoliberal presentaba una fragilidad económica y productiva. Así, muchos empresarios se veían obligados a bajar las cortinas de sus fábricas, debido a la liberalización del mercado, las bajas barreras aduaneras que permitían la invasión de productos importados en el

7 Ley Nacional N² 23.696, 1989.

8 Ley Nacional N²3.697, 1989.

9 Palermo \& Novaro, 1996.

10 Ley Nacional N²3.938, 1991. 
mercado interno en detrimento de la industria nacional, la supremacía de la valorización financiera sobre la producción, la falta de competitividad a nivel internacional, la sobreestimación de la cotización del dólar y la falta de la decisión política para romper los lazos con el Fondo Monetario Internacional atendiendo así las necesidades del país.

Por otro lado, es pertinente para este trabajo mencionar que una de las normas sobre las que se basaba la seguridad jurídica del modelo menemista era la Ley de Concursos y Quiebras. ${ }^{11}$ Esta legislación establecía que en caso de quiebra en los establecimientos fabriles, el juez del fuero comercial que atendiera la causa, debía realizar un inventario de la fábrica y proceder al desalojo de la misma y la clausura del recinto, instaurando además que quienes heredaban los bienes de las empresas, no debían hacerse responsables por el futuro de los empleados que pertenecían a las mismas, es decir, expresaba que "elpersonal de una empresa que iba a quiebra perdía todos los derechos y la condición de trabajador en la misma." 12

Por todo lo dicho y en sintonía con lo que sostiene Svampa, se puede decir que la aplicación de las políticas neoliberales que conllevaron una fuerte desregulación económica y una reestructuración global del Estado, terminó por acentuar las desigualdades existentes y generaron nuevos procesos de exclusión, ${ }^{13}$ procesos que como veremos a continuación, tuvieron su impacto en la provincia de Córdoba.

\section{Los estudios sobre el neoliberalismo en Córdoba}

El estudio sobre los efectos de las políticas neoliberales en la provincia cuenta con un número significativo de publicaciones. Una de las líneas más trabajadas gira en torno a las protestas de fin de siglo contra el modelo resultado de un sustancial trabajo realizado por Mónica Gordillo y otros. ${ }^{14}$ Dicho estudio analiza cómo se fue abriendo camino el neoliberalismo en la provincia en sus diferentes gobiernos a lo largo de la

11 Ley Nacional No 24.522, 1995.

12 Rodríguez 2007:147.

13 Svampa 2005.

14 Gordillo, Arriaga, Franco, Medina, Natalucci \& Solís, 2012. 
década de los noventa y qué concepciones tenían cada uno sobre el Estado al tiempo que permite identificar cómo fue la dinámica de la protesta que hicieron frente al modelo dentro del espacio cordobés como así también los sectores y conflictos propios de cada etapa.

Siguiendo la lógica del análisis sobre las políticas económicas del neoliberalismo, Gordillo establece que el proceso de ajuste y reforma de los Estados provinciales se desarrolló de manera tal que pueden distinguirse tres fases: ${ }^{15}$ la primera a partir de 1990, cuando el gobierno central inició el recorte financiero a los bancos provinciales; la segunda partir de 1992, que consistió en la reducción presupuestaria del gasto en salud, asistencia social, educación y cultura y en la eliminación de los ramales ferroviarios; la tercera - y la que más interesa en este trabajo - en 1994, mediante el pacto fiscal que institucionalizó el recorte de los recursos coparticipados. A partir de este momento, sumado a la visibilidad que comenzarían a adquirir los costos sociales de las reformas, los escenarios provinciales se convertirían en lugares de movilización social, algo sobre lo que se volverá más adelante.

En la provincia de Córdoba la incidencia de las políticas neoliberales se manifestó en la desindustrialización y en una creciente concentración de la actividad económica en manos privadas. Así "la presencia de grandes multinacionales corrió en paralelo con la tercerización de la economía y fue acompañada de la expulsión de mano de obra, en sintonía con la dinámica económica nacional."16

Córdoba fue una de las primeras provincias en tomar la iniciativa de sancionar una ley de reforma provincial como lo requirió el ejecutivo nacional. A fines de 1989 Eduardo Angeloz presentó a la legislatura un proyecto de reforma cuyo objetivo era redefinir las funciones del Estado e incorporar capitales privados a partir de una reestructuración de la administración basada en la descentralización e incluso la privatización; lo que sería la expresión jurídico-política del modelo cordobés de reforma del Estado.

A mediados de la década el modelo cordobés entró en crisis y con la llegada anticipada al ejecutivo provincial de Ramón Bautista Mestre, entre 1995 y 1999 se llevó a cabo

15 Gordillo, 2012.

16 Arriaga, Franco, Medina \& Natalucci 2012: 25. 
buena parte del ajuste y la reestructuración del Estado provincial postergado y/o bloqueado hasta entonces. Mestre puso en marcha un ajuste "por shock" en el marco del cual se sancionó, entre otras medidas, una ley de emergencia que supuso fuertes recortes a los derechos de los trabajadores. ${ }^{17}$

Coincidiendo con la reelección del presidente Menem, Córdoba adhirió al Pacto Fiscal, un acuerdo con el gobierno nacional sobre el presupuesto que éste garantizaría a las provincias regulando a qué sería destinado, en función de las recomendaciones del FMI y el Banco Mundial. Esto implicó el compromiso de avanzar en el diseño de políticas tendientes a la privatización de los bancos y de las empresas provinciales de servicios públicos, en la transferencia de la Caja de Jubilaciones a la Nación y la reforma del sistema de salud y educación pública. El gobernador radical no se propuso simplemente un ajuste, sino que con él concretó una redefinición de las modalidades de vinculación entre el Estado y la sociedad a nivel provincial, constituyéndose como un gobierno de transición hacia la desarticulación del Estado de bienestar y de su reorganización bajo postulados neoliberales.

Lo primero que se puso en la mira fue el llamado gasto público en materia de salarios y servicios públicos ${ }^{18}$ ante esta situación la provincia comenzó a mostrar signos de crisis estructural y como consecuencia de la caída en las ventas, los despidos en el sector industrial y la crisis general de la actividad comercial, la quiebra de fábricas, el desmantelamiento de ferrocarriles y el cierre de plantas automotrices se hizo evidente.

\section{Formas de resistencia al neoliberalismo}

Córdoba se encontraba cada vez más afectada por las políticas económicas del neoliberalismo y a raíz de ello los conflictos comenzaron a hacerse más frecuentes. Aparecieron entonces nuevas formas de resistencia y militancia y se resignificaron estrategias para llevar a cabo prácticas políticas en espacios públicos que buscaron

17 Ley provincial No 8.482, 1995.

18 Arriaga, Almada, Carini, Gleser, Puttini \& Valdemarca, 2018. 
imponerse al modelo económico neoliberal dando lugar a repertorios de lucha asociados a la acción directa y a nuevos formatos organizativos. ${ }^{19}$

$\mathrm{Al}$ respecto Arriaga y otros autores ${ }^{20}$ llevan adelante un minucioso análisis sobre la dinámica de las protestas, los sectores y los conflictos que se presentaron a lo largo de la década del noventa en la provincia y utilizan la categoría acción colectiva de protesta considerando que éstas se pueden relacionar con las características del sistema político. Además, postulan que su especificidad estaría dada por la intención de confrontar con un oponente definido a partir de la elaboración de una demanda que se intenta instalar y legitimar en el espacio público recurriendo a un lenguaje de derechos.

Por su parte, Medina \& Franco, proponen comprender a las acciones colectivas como "acciones de cualquier tipo que requieren de la participación cooperativa de al menos dos individuos en su realización y que suponen adscripciones identitarias, más o menos precarias e inestables. ${ }^{211} \mathrm{La}$ acción colectiva será orientada al sostenimiento de una demanda - en general con referencia directa o indirecta al Estado. En este sentido, cabe remarcar que "la noción se limita a partir de su carácter contencioso e intencional, por un lado, y de su visibilidad pública, por el otro. ${ }^{, 22}$

En esta línea, y de acuerdo con lo que sostiene Alberto Melucci, ${ }^{23}$ se considera que una acción colectiva es el resultado de intenciones, recursos y límites, es decir una orientación intencional construida mediante relaciones sociales desarrolladas en un sistema de oportunidades y obligaciones. Para el sociólogo italiano, los individuos que actúan colectivamente construyen su acción mediante inversiones organizadas que dotan de sentido el estar juntos. Estas acciones colectivas de protesta toman distintas formas y se transforman según el proceso que atraviesan, conformando así lo que Charles Tilly denomina repertorios de acciones colectivas, es decir transformaciones, bien definidas y limitadas, que son particulares a diversos actores, objetos de acción y

19 Svampa, 2005.

20 Gordillo, 2012.

21 Medina \& Franco, 2011: 4.

22 Schuster, 2005: 56.

23 Melucci, 1994. 
lugares, circunstancias estratégicas y que, además, permanecen flexibles, sujetas a negociación e innovación. ${ }^{24}$

Interesa aquí el periodo que se extiende desde 1995 a 1999, momento en el que Córdoba se ve atraída por nuevos e importantes planes de inversión, al tiempo que se perfilaban paulatinamente pautas flexibilizadoras y de nuevos sistemas de organización del trabajo que poco a poco irán limitando la incorporación de mano de obra e incluso amenazando con su sistemática reducción y debilitando el poder de presión de los sindicatos. A partir de este momento, "las demandas propias para enfrentar la situación fueron perdiendo sus rasgos ofensivos, predominantemente de reivindicaciones salariales para centrarse más en la defensa de los puestos de trabajo" ${ }^{25}$ tal es el caso del análisis que desarrollaremos a continuación.

\section{El conflicto de la Cervecería Córdoba}

Por las calles de barrio Alberdi se respira lucha, pues en este tradicional barrio de la ciudad de Córdoba se evidencian las marcas de la memoria de hechos históricos muy significativos. La Reforma Universitaria en 1918 y el Cordobazo en 1969, fueron dos acontecimientos que marcaron la historia del movimiento obrero - estudiantil cordobés. En este tradicional barrio de la ciudad cordobesa, en 1912 fue puesta en funcionamiento la Cervecería Córdoba a manos de los Meyer, una familia de ciudadanía alemana que dirigió la fábrica personalmente hasta el año 1951, cuando el gobierno de Perón dispuso un usufructo del Estado y entonces pasó a ser Fábrica Obrera Cervecera Argentina Sociedad Anónima (FOCASA) y a contar con capitales estatales y también de la Federación Obrera Cervecera. El golpe de Estado de 1955 devolvería la fábrica a los Meyer, que quedaría esta vez en manos de los hijos de los fundadores hasta los setenta, cuando el grupo Cafiero se hizo poseedor de la planta fabril.

24 Citado en Alonso, 2012.

25 Gordillo, 2012: 87. 
La fábrica pasó por diferentes dueños, pero los momentos más críticos se vivieron entre 1997 y 1998. En 1997 su propietario Ríos Seoane se declaró en quiebra y los trabajadores cerveceros se expresaron en lucha contra las condiciones que imponía la ley de quiebras y mediante la ocupación de la planta fabril reclamaron la continuidad de sus puestos de trabajo. Atendiendo a esta exigencia, el juez interviniente en la causa Carlos Tale, dio lugar a lo planteado por los cerveceros permitiendo el alquiler de la planta, mientras la justicia debía convocar a licitación para la adjudicación definitiva del establecimiento. Los trabajadores lograron que en el pliego de la licitación quedara establecido que el nuevo propietario debía comprometerse a mantener la fábrica en funcionamiento, incluyendo al personal en funciones al menos por cinco años, lo que chocaba directamente con la Ley de Quiebras del menemismo.

El pliego de reivindicaciones de los trabajadores establecía:

La venta de la empresa en funcionamiento, supone que incluye al personal que actualmente se encuentra en funciones, ello sin perjuicio de la irrestricta vigencia de cuanto dispone el art. 199 de la normativa concursal y de los convenios que el personal hubiere celebrado o celebre con el actual locatario para la EVENTUALIDAD que el mismo resulte adjudicatario ${ }^{26}$

A la licitación de la Cervecería se presentaron dos propuestas. Por un lado, la del empresario cordobés Jorge Stabio, quien había alquilado la planta durante los últimos meses y se comprometía a respetar lo establecido en el acta; por el otro CICSA (Compañía Industrial Cervecera Sociedad Anónima) - una subsidiaria argentina del grupo monopólico CCU-LUCSIK (Compañías Cerveceras Unidas - Lucsik) - con una oferta que duplicaba a la de Stabio. En marzo de 1998 CICSA ganó la licitación, teniendo como propósito cerrar la fábrica. ${ }^{27}$

Si bien al principio entre los trabajadores el reclamo se centró en el cobro de la indemnización, con el paso de los días y tal como se explicó con anterioridad, las acciones colectivas de protesta se fueron concentrando cada vez más en la preservación de la fuente de trabajo. Así, al enterarse de que "la compañía no tomará

26 Pliego de condiciones generales para la venta de los bienes materiales e inmateriales de la fábrica. s/f, Ccolección personal de Pedro, ex trabajador de la Cervecería Córdoba y dirigente sindical durante el conflicto. Actualmente empleado público.

27 Ledesma \& Montes, 1999. 
posesión efectiva de las instalaciones de Cervecería Córdoba mientras el personal siga trabajando u ocupando las instalaciones", ${ }^{28}$ el 4 de mayo de 1998 los ciento sesenta y seis trabajadores junto a sus familias decidieron tomar la fábrica.

Un panfleto diseñado por los propios obreros resume cuál era su posición respecto al conflicto:

Con nuestros dirigentes a la cabeza y sostenidos por la razón que nos ganamos durante ocho meses de lucha contra la quiebra fraudulenta, logramos el pliego de condiciones por el cual la Cervecería Córdoba salió a la venta, que obligaba al comprador a continuar con la explotación fabril y mantener la fuente de trabajo para más de un centenar y medio de trabajadores por un plazo no menor de cinco años. Para ello el juez. obligó a Stabio a dejar los depósitos con cerveza para continuar con la explotación. Cuestionamos y aprovechamos las contradicciones de la Ley de Quiebras poniendo en serios riesgos el sistema jurídico del modelo de Menem y Mestre y la tan mentada seguridad jurídica para los capitales que vienen a invertir 29

Ante la negativa de los cerveceros a abandonar la fábrica, el grupo chileno Cicsa-Luksic "ratificaba su interés por la Cervecería Córdoba, por lo cual estaba dispuesta a aguardar la resolución del conflicto judicial que se habia planteado en torno a la planta de barrio Alberdi". ${ }^{30}$ Cicsa sostenía que había comprado la marca y la planta sin empleados, mientras que el gobierno de Córdoba, aunque significara una situación complicada, según la prensa no estaba dispuesto a cargar con un desalojo con represión. ${ }^{31}$

Sin embargo, tras varios intentos y amenazas de desalojo, el 17 de agosto a las cuatro de la madrugada la policía desalojó la planta de la Cervecería Córdoba en un eficaz y sorpresivo operativo. Con miembros de fuerzas policiales especiales y del cuerpo de bomberos redujeron rápidamente a los gremialistas y trabajadores - algunos acompañados de sus familias - que permanecían en el interior del establecimiento. Posteriormente, cerca del mediodía, un grupo de manifestantes que pedía por la liberación de los detenidos fue violentamente reprimido en la Plaza San Martin y zona céntrica, con algunos detenidos. ${ }^{32}$

28 La Voz del Interior, 2 de mayo de 1998.

29 Panfleto. Colección personal de Pedro. (s.f)

30 La Voz del Interior, 2 de julio 1998.

31 La Nación, 3 de julio de 1998.

32 La Voz del Interior, 18 de agosto de 1998. 
Cuatro meses después de lo previsto, el 29 de agosto, y luego de que la justicia fallara en contra del reclamo de los trabajadores, Cicsa tomó posesión de la planta con maquinarias y producto apto para el consumo, el cual había sido rigurosamente cuidado por los trabajadores durante la toma.

Hoy, la fábrica de barrio Alberdi no produce cerveza y en su lugar se ha construido un moderno complejo de departamentos denominado Antigua Cervecería. Fueron ciento cinco días en los que los trabajadores junto a sus familias intentaron evitar el cierre de la fábrica y a partir de acciones colectivas de protesta y resistencia buscaron disputar los espacios tanto en el interior de la planta como en sus alrededores. El apoyo de las mujeres que acompañaban la lucha y la pelea por la fuente de trabajo de sus familiares varones y el de los vecinos, estudiantes, artistas, agrupaciones de izquierda y de otros gremios, fue uno de los aspectos más importantes. Según los diarios locales se trató de la toma más larga de la historia obrera cordobesa, hasta el momento. ${ }^{33}$ Los empleados de la Cervecería Córdoba creían representar para otros trabajadores y dirigentes gremiales un estilo distinto de resistencia o de forma de lucha. ${ }^{34}$

En ocasión de cumplirse veinte años de la toma de la fábrica algunos de los ex trabajadores reflexionaron sobre la importancia que tuvo para ellos, sus familias y la población cordobesa en general la experiencia de los ciento cinco días de toma y la lucha por la fuente de trabajo en un contexto marcado por una gran crisis política y económica, tanto a nivel nacional como provincial.

Fue una experiencia muy significativa. El aguante de la familia, los vecinos, los estudiantes universitarios y la solidaridad con otros sectores en conflicto y con compañeros de otras empresas que estaban siendo víctimas de las politicas del gobierno [...] los cierres y las privatizaciones. La unión de los obreros pechando para el mismo lado, todos bajo el mismo objetivo que era mantener la fuente de trabajo. Creo que lo que más me marcó fue el hecho de que estábamos todos a la par, todos éramos iguales, no existían orgullos. Un hecho que muestra que para obtener algo siempre hay que luchar. Para lograr que se respeten los derechos, hay que luchar en unión ${ }^{35}$

33 La Voz del Interior, 4 de julio de 1998.

34 La Voz del Interior, 4 de julio de 1998.

35 Testimonio de Pedro, ex trabajador de la Cervecería Córdoba y dirigente Sindical durante el conflicto. Actualmente empleado público. Entrevista realizada por Fátima Boccetti, 17 de agosto de 2018. 
Creo que marcó Córdoba. En la provincia no bubo una lucha como esa nunca más, no bubo más un paro como el de esa época con enfrentamientos de los obreros y los estudiantes con la policía. El conflicto de la Cervecería fue como una luz a través del túnel, una llama de enseñanza para todos aquellos que intentan cambiar la bistoria, la politica de este país, que se sigue repitiendo a pesar de que ha babido luchas históricas y compañeros que han dejado su vida ${ }^{36}$

Personalmente, para mí fue el hecho que me cambió la vida para siempre [...] fue una lucha que terminó de desgastar al gobierno de Mestre y la politica de reforma del Estado [...] me parece que la lucha de la Cervecería fue parte de un camino que va recorriendo el movimiento obrero y nuestro pueblo para encontrar las maneras de enfrentar estas politicas ${ }^{37}$

La Cervecería Córdoba nunca más abrió sus puertas para la producción, sin embargo, la toma de la fábrica quedó incorporada para siempre en la gran tradición de lucha que representa al barrio Alberdi.

\section{Las mujeres en el conflicto cervecero}

La comprensión del concepto género ha llegado a ocupar un lugar especial en la historiografía reciente, ubicándose en el centro de uno de los debates políticos más trascendentes: el del papel de las mujeres en la sociedad. El uso de tal categoría permite:

...reconocer distintas formas de interpretación, simbolización y organización de las diferencias sexuales en las relaciones sociales, dirigiendo la crítica a la idea de la existencia de una esencia femenina y a las elaboraciones culturales que naturalizan las relaciones de poder y subordinación establecidas entre hombres y mujeres $^{38}$

Se parte de la idea de que el género es un elemento constitutivo de las relaciones sociales basadas en las diferencias que distinguen los sexos, a la vez que es una forma

36 Testimonio de Daniel, ex trabajador de la Cervecería Córdoba y dirigente Sindical durante el conflicto. Actualmente secretario general de la CTA Autónoma de Córdoba. Disponible en http://comunismorevolucionario.org/crpmlm/cerveceria-cordoba-105-dias-de-toma-que-marcaronun-camino/

37 Testimonio de Dante, ex trabajador de la Cervecería Córdoba y dirigente sindical durante el conflicto. Actualmente es el presidente del Centro Vecinal del Barrio Alberdi. Disponible en http://comunismorevolucionario.org/crpmlm/cerveceria-cordoba-105-dias-de-toma-que-marcaronun-camino/

38 Ortale, 2015: 18. 
primaria de relaciones significativas de poder. ${ }^{39}$ Entendido como una construcción socio-cultural, el género, se encuentra rodeado de representaciones, prácticas, conceptos y dispositivos discursivos que buscan redefinir lo masculino y lo femenino junto a los comportamientos propios de cada uno de ellos.

En el entramado del discurso clásico, el espacio social se divide entre la esfera pública y la esfera privada, estableciendo desde el punto de vista político y económico, y desde una dimensión genérica, claras diferencias que responden a la existencia de un contrato social $^{40}$ en donde lo público, lo productivo, el poder, la responsabilidad de asegurar el bienestar material del hogar y lo masculino se oponen a lo privado, lo reproductivo, el afecto, la domesticidad y lo femenino.

En términos generales, cuando vinculamos género con historia reciente y protestas, las mujeres aparecen apropiándose del acto político social, se visibilizan cuestionamientos a la lógica de articulación de la sociedad, al expresar la presencia y reivindicaciones sociales poniendo a la vista una nueva forma de relacionar lo político con lo social, lo privado con lo público, lo productivo con lo reproductivo. Aparece aquí la consigna feminista "lo personal es político", iluminando la idea de que "los problemas 'personales" solo se pueden resolver a través de medios y acciones políticas". ${ }^{41}$

Así, los procesos de politización que se expresan a partir de las necesidades de las mujeres y la construcción de nuevas subjetividades que resultan de su participación colectiva, "obligan a revisar la supuesta homogeneidad de lo femenino y hace posible pensar en construcción de proyectos politicos que incorporan la diferencia como instancia articuladora de las perspectivas de clase y de género". ${ }^{2}$

Para comprender los repertorios de acción colectiva adoptados por mujeres en determinados contextos de conflicto social, Kaplan acuñó el término conciencia

39 Scott, 1996.

$40 \mathrm{Al}$ respecto Carole Pateman realiza un análisis crítico en su obra El contrato sexual en donde plantea que "el pacto originario es tanto un pacto sexual como un contrato social, es sexual en el sentido de que es patriarcal - es decir, el contrato establece el derecho político de los varones sobre las mujeres - y también es sexual en el sentido de que establece un orden de acceso de los varones al cuerpo de las mujeres: "El contrato está lejos de oponerse al patriarcado; el contrato es el medio a través del cual el patriarcado moderno se constituye", Pateman, 1995: 11.

41 Pateman, 1996:16.

42 Ortale, 2015: 38. 
femenina ${ }^{43}$ que hace referencia a la asunción por parte de las mujeres del deber de cumplir con su rol social. Según la autora, la conciencia femenina crea un sentimiento colectivo de derechos y obligaciones, resultado de la interiorización del lugar que ocupan las mujeres en la división sexual del trabajo, que las predispone hacia argumentos políticos en temas sociales. Las mujeres con conciencia femenina exigen los derechos que sus obligaciones llevan consigo, y el impulso colectivo necesario para asegurar estos derechos puede llegar a desarrollar una fuerza que acabe politizando las redes de relaciones de la vida cotidiana.

Diversos estudios se han encargado de exponer y problematizar los lazos que la historia reciente ha tejido con la historia de las mujeres y los estudios de género en el seno de la historiografía argentina de las últimas décadas. El vínculo de la historia de las mujeres con la historia de la conflictividad política y social de nuestro país, exige que nos detengamos en el género como una de las facetas que emergen de la mayoría de los testimonios orales. "Cuando narramos historias de vida lo hacemos desde la perspectiva de nuestro género, pues narrar desde el propio género también aporta a los relatos orales una suposición socializada de cómo deberíamos comportarnos". ${ }^{4}$

Este trabajo muestra una primera aproximación a las fuentes orales mediante una fase exploratoria de entrevista, abriendo paso a la disposición de otras mujeres a contar su experiencia en el conflicto de la Cervecería Córdoba. Se considera que a partir de este recurso no sólo se puede obtener información de hechos sino también expresión y representación de experiencias, pues en los relatos están presentes las dimensiones y sentidos de la memoria.

Siguiendo a Pasquali, "el género tanto como la situación económico-social, debe ser vislumbrado como constituyente central de las múltiples aristas que arman las experiencias humanas y, al hacerlo las van conformando según el momento en que ocurren." $45 \mathrm{El}$ agravamiento de la crisis económica a nivel nacional y provincial puso en el tapete la centralidad del rol doméstico, ya que eran las mujeres las que debían administrar el hogar con recursos cada vez más escasos. En esta línea, las respuestas fueron muchas: marchas contra las

43 Kaplan, 1990.

44 Pasquali, 2013: 171.

45 Pasquali, 2013: 175. 
tarifas y por la defensa de los puestos de trabajo, organizaciones de ollas populares, colectas, entre otras.

Alejandra Vasallo considera que el concepto de esfera pública y su relación con la acción política son fundamentales para analizar la organización y la acción colectiva de las mujeres argentinas, y por ella entiende "tanto el territorio discursivo de la deliberación y la acción colectiva que tiende al supuesto bien común, como a los espacios reales de deliberación y acción, por fuera de los límites del hogary el parentesco, y en el marco de instituciones sociales". ${ }^{46}$

Las mujeres aparecieron allí donde no se las esperaba. Al incorporar y apropiarse de las acciones políticas sociales se visibilizaron, pero al mismo tiempo se encontraron, al pensarse a sí mismas y pensar nuevas acciones, experiencias y presencias, en tensión con los modelos tradicionales. Mujeres con distintas trayectorias culturales, diferentes clases sociales y disímiles biografías dejaron de lado esas diferencias e irrumpieron en el espacio público con acciones y estrategias propias, para visibilizar sus problemáticas y expresar una denuncia pública que interpelara a la sociedad, construyendo sentidos, significados, expectativas, formas de concebir(se) y percibir(se) en la sociedad al tiempo que configuraron una identidad como sujetos políticos activos.

En nuestro estudio, podemos observar que los modos en los que se acompañaban las familias cerveceras muestran las raíces de una cultura de clase que excede a los trabajadores y sus lugares de trabajo. La participación de las mujeres durante el conflicto contribuyó en cierta medida a su organización y eficacia. Como sostiene Palermo, lo que estaba en juego no era en esencia los derechos de los trabajadores sino las necesidades del hogar proletario. ${ }^{47}$ Los hogares cerveceros estaban marcados por la inestabilidad producto de la crisis económica y frente a la incertidumbre por el deterioro de las condiciones laborales del "jefe de familia", la falta de ingresos fijos, la pérdida del poder adquisitivo, el aumento del costo de vida y la necesidad de los hijos e hijas, las mujeres tenían -sentían- no el derecho sino la obligación de involucrarse en la protesta, "construyendo su participación política a partir de su condición de madres y esposas, y asumiendo tareas y actitudes tradicionalmente asociadas a la feminidad: alimentar, cuidar y proteger

46 Vasallo, 2000: 174.

47 Palermo, 2011. 


\section{a la familia". ${ }^{48}$}

Dora Barrancos establece que la sustentabilidad de los procesos de lucha, reposan en gran medida sobre los cuerpos femeninos ${ }^{49}$, pues, a decir de Andújar, se puede establecer que la presencia de las mujeres en este acontecimiento puede explicarse teniendo en cuenta que los sectores sociales oprimidos y sobre todo las mujeres, hacen su aparición cuando se presentan escenarios históricos en los que las crisis sociales se agudizan, pues el impacto de tal crisis en la organización de la vida cotidiana es genéricamente diferencial y somete a las mujeres a un plus de frustración y violencia social eludible para los varones. ${ }^{50}$

Las mujeres cerveceras eran las que estaban en los hogares y conocían las necesidades de sus hijos, eran ellas las que debían hacer maniobras para que el dinero les alcanzara. En oportunidad de un intento de negociación, las mujeres tomaron la palabra y fueron sus planteos desde el vivir día a día lo que llevó a no aceptar un subsidio que duraría sólo unos meses, y continuar con la defensa de la fuente de trabajo.

Durante los ciento cinco días de toma, antes y después, Adriana desde su lugar de madre y esposa decidió acompañar a su marido y defender juntos la fuente de trabajo. Dedicada cien por ciento al cuidado de sus hijos y del hogar, debió traspasar las fronteras de lo privado y enfrentarse a un nuevo espacio social, desconocido hasta entonces para ella.

Respecto a su experiencia durante este tiempo de lucha ella recuerda:

El secretario de trabajo nos ofrecía un subsidio por un par de meses para que abandonáramos la toma. Algunos lo querían, pero otros no lo queríamos porque no nos convenía. Íbamos a vivir ocho meses con ese subsidio, pero después quedábamos sin nada. Y yo qué les decia a mis hijos: hasta acá llegó el subsidio, no comen más. Eso lo planteamos y por eso se decidió no aceptar esa oferta ${ }^{51}$

A lo largo del conflicto las mujeres cerveceras ocuparon diversos espacios que ponen en jaque la dicotomía publico/privado. Uno de ellos tiene que ver con el lugar que

48 Ramos Ávila, 2004: 4.

49 Barrancos 2012.

50 Andújar, 2010.

51 Testimonio de Adriana, participó junto a su marido y sus hijas e hijos en la Toma de la Cervecería Córdoba. Entrevista realizada por Fatima Boccetti, 14 de septiembre de 2018. 
ocupaban en los hogares, imbricado sobre lo íntimo y privado. El cuidado de sus hijos como así también de la economía familiar y de los gastos diarios fue su principal rol, además de acompañar a sus maridos, sin embargo, este espacio con la toma se convierte en un lugar más amplio e interconectado, lo íntimo o privado se vuelve colectivo. Adriana hace una pausa en la conversación y recuerda cómo acompañó a su marido y cómo era el mecanismo que tenían previsto, ella y el resto de sus compañeras de lucha y resistencia, cuando la amenaza de desalojo de la fábrica rondaba en sus hogares.

...brindándole palabras de aliento y estando pendiente del teléfono. Ante la amenaza de desalojo, las Ilamadas telefónicas eran el medio que teníamos para comunicarnos entre nosotras y coordinar la llegada a la fábrica para acompañar a nuestros maridos en ese momento de defensa de sus puestos de trabajo, que en definitiva era defender a la familia

Defender a la familia, una frase que se hace recurrente en el relato de la entrevistada. No se trataba de resistir sólo porque tenían el derecho de hacerlo y de defender la fuente de trabajo, ellas en su rol de madres, esposas y administradoras del hogar, sentían la obligación de involucrarse en la lucha y no sólo defender un puesto de trabajo sino primordialmente "defender a su familia".

Impulsadas por las necesidades del hogar y del cuidado de la familia, las mujeres comenzaron a organizarse rompiendo los límites de lo privado; planificando eventos y siendo las principales protagonistas en los mismos, su organización y resistencia empezó a ser visible también en lo público.

...las peñas, haciamos choripán para vender con chorizos que a veces nos donaban o empanadas también con carne que nos donaban, o locro... Íbamos a los bailes de La Mona o a la cancha de Belgrano con una urna que tenía una inscripción que decía que perteneciamos a la Cervecería Córdoba, de esa manera recaudábamos plata y la repartíamos, no entre todos y no en partes iguales. $L a$ mayor parte de lo recaudado se destinaba a los que tenían que pagar alquiler o algún crédito y a los que realmente no tenían. Recaudábamos para subsistir nunca se nos pasó por la cabeza gastar esa plata en elementos para pelear contra la policía, por ejemplo

El relato de Adriana muestra cómo se fueron forjando lazos de solidaridad, no sólo entre ellas y sus familias, sino también con la comunidad barrial. Y una vez más 
aparecía la preocupación por la economía del hogar, y el rol de amas de casa que se encargaban de cocinar, ya no sólo en sus hogares, ahora también en la fábrica. La proximidad física contribuyó al poder de la comunidad femenina y a forjar la idea de conciencia entre ellas, "estas redes laxas facilitan los estrechos vinculos que muestran su fuerza en momentos de acción colectiva. ${ }^{52}$

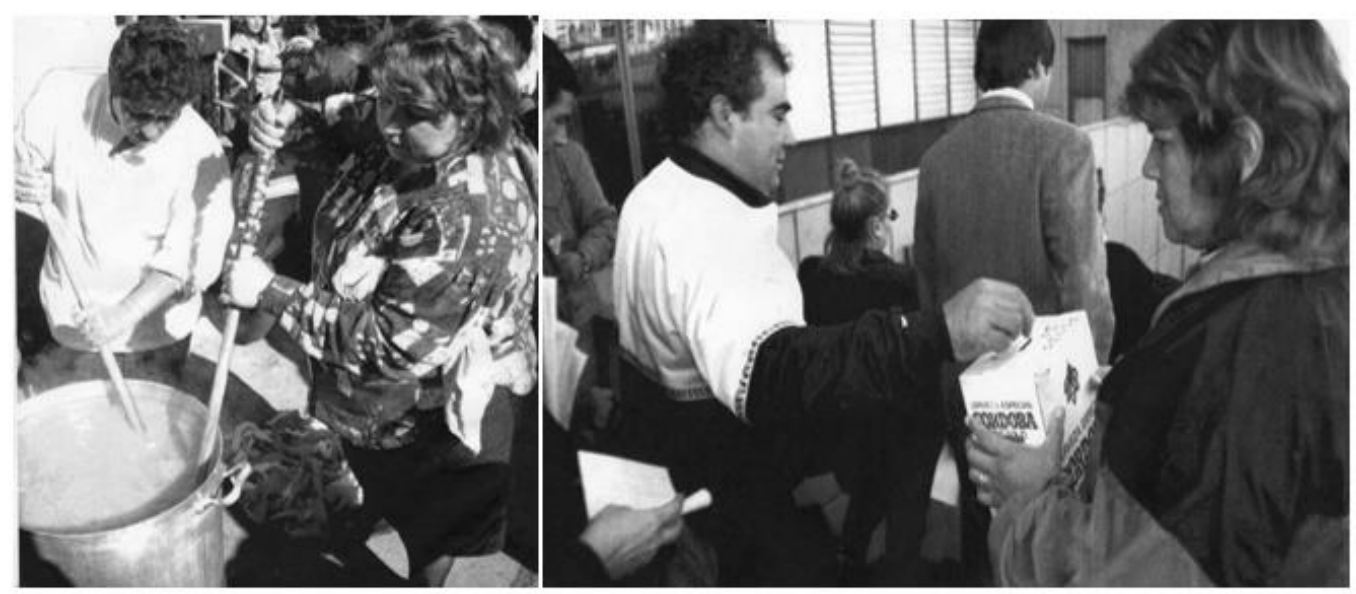

Mujeres realizando acciones para recaudar dinero. Archivo ex trabajadores de la Cervecería Córdoba

Motivadas por las necesidades propias del hogar y la urgencia de una respuesta al reclamo por la fuente de trabajo de sus compañeros varones, las mujeres ocuparon un nuevo escenario: la calle. El relato de Adriana y varios registros fotográficos y audiovisuales permiten observar que eran ellas quienes encabezaban las manifestaciones.

Cuando se sabía que íbamos a marchar, nos cerraban las calles y de a una o de a dos nos íbamos metiendo e íbamos acercándonos a la casa de gobierno. Era la forma de reclamar directamente a las autoridades

52 Kaplan, 1990: 270. 


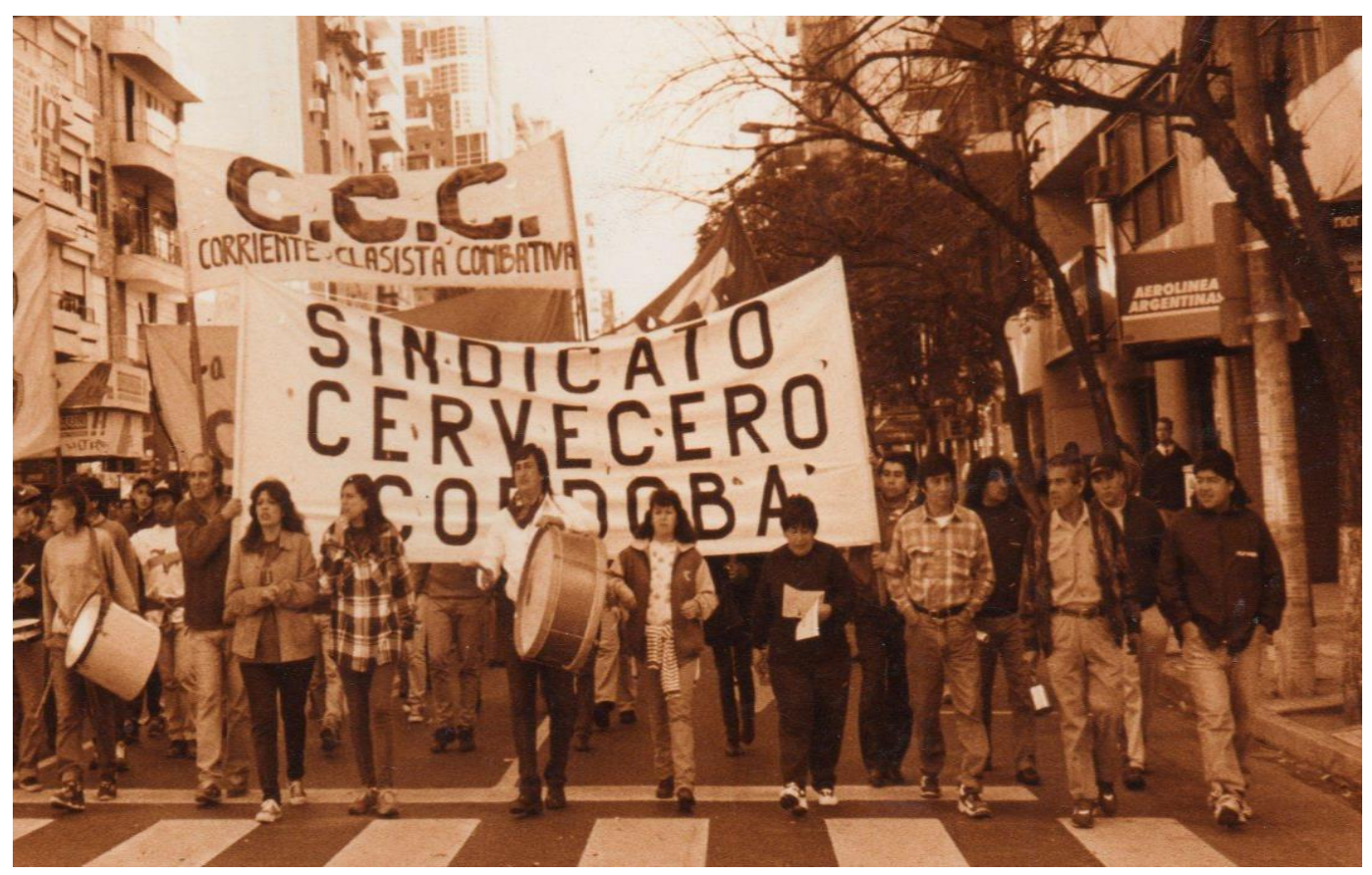

Mujeres encabezando las columnas de las manifestaciones en las calles de la ciudad de Córdoba. Archivo ex trabajadores de la Cervecería Córdoba.

En una de las amenazas de desalojo, cuando la noticia llegó a los hogares cerveceros, las mujeres acudieron inmediatamente a la planta; esta noche es recordada como "La noche de las botellas rotas", la entrevistada expresa:

Rompimos botellas de cerveza y llenamos la Arturo Orgaz de vidrio. Desde la cancha hasta la otra esquina. Porque según se decía la policía venía a caballo asi que, con vidrio en los alrededores, los caballos no iban a pasar. 


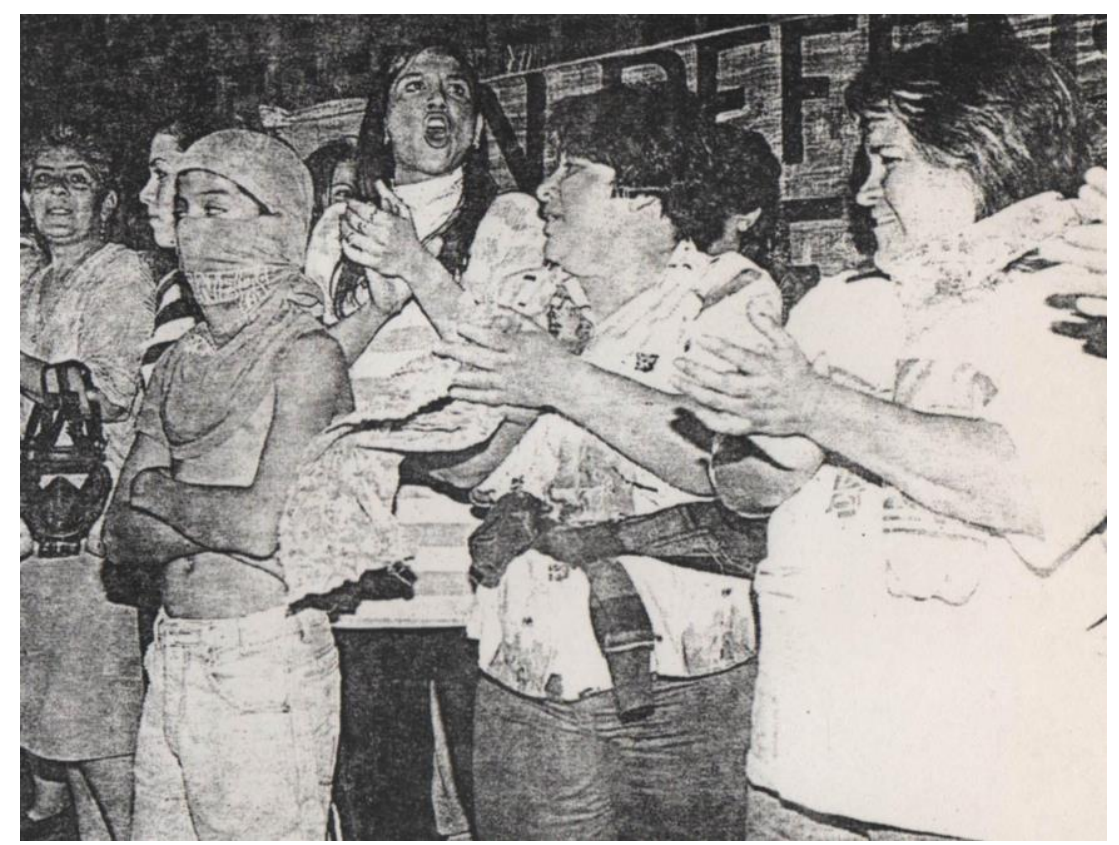

Mujeres resistiendo ante un intento de desalojo. La Voz del Interior 9 de mayo de 1998

Durante los ciento cinco días que duró el conflicto, las mujeres fueron irrumpiendo en el espacio público con diversos repertorios de acción colectiva. Dotadas de conciencia femenina, llegaron a enfrentarse con autoridades y participaron en instancias de negociación con el abogado, el ministro de trabajo y el juez. Adriana recuerda que en algunas reuniones lo hacían de manera directa frente a las profesionales, aunque la mayoría de las veces, la participación era indirecta, desde el diálogo con sus maridos.

...muy pocas veces porque los hombres mucho no nos dejaban. Habia un grupo de hombres que no nos dejaban participar ni opinar. Ellos decian que nosotras no teníamos que estar en esos lugares. Para ellos nosotras teníamos que estar... por ejemplo cuando salíamos a las calles, nos poniamos al frente para que no golpearan a los hombres. Éramos como el escudo de algunos de ellos. No todos pensaban así la mayoria nos incluian y nos motivaban a participar en las reuniones. $Y$ de hecho ayudó mucho, porque el hombre bablaba desde su trabajo, pero nosotras hablábamos desde la casa, desde la familia, desde ser mamá, de saber las necesidades que tenian nuestros hijos. Ellos peleaban por su fuente de trabajo. Nosotras por las necesidades de los hijos

El relato deja al descubierto las diferencias entre los géneros. Vasallo, dice que éstas, así como las diferencias de clase o las étnicas, organizan a la sociedad en términos desiguales y jerárquicos y que se expresan "tanto en el nivel de las instituciones que se imponen 
por medio de relaciones de poder, como en los imaginarios que excluyen a la mujer" 53 en la inserción en las diversas ramas de la producción y también en lo relativo a la práctica sindical, social o política.

De ahí la importancia de un estudio sobre el conflicto en perspectiva de género. Sin embargo, es pertinente tener en cuenta que las fronteras de género "son a menudo móviles y negociables ${ }^{` 54}$ el sistema de género no asigna funciones sociales según bases biológicas preestablecidas, sino que depende de formaciones culturales y sociales históricas. Algunas de las mujeres cerveceras, tenían esto en claro, y a pesar de cualquier diferencia de género que pudiese presentarse ante el reclamo de los trabajadores, como en la sociedad en general, llevaron a cabo una participación activa en el proceso de toma de los espacios, emergiendo como sujetos políticos con nuevas formas para hacer, ser y decir en el espacio público. Así, desde una perspectiva de género, se entiende a las acciones colectivas en clave de politización y repolitización de las mujeres cerveceras, que desarrollaron sus prácticas y acciones en los márgenes del circuito doméstico en un contexto fuertemente convulsionado, cuyo objetivo no era sólo expresarse sino transformar la realidad.

Como se mencionó, los ciento cinco días de conflicto forjaron lazos de amistad y solidaridad entre las mujeres cerveceras, los niveles de confianza alcanzados durante la protesta hicieron que dejaran de ser individuos librados a su suerte para tornarse en un colectivo social dispuesto a luchar unido para cambiar su destino. Esos lazos de amistad y solidaridad no incluían sólo a las mujeres madres de familia cerveceras, sino también a hijas, hermanas, madres, suegras y cuñadas de los trabajadores, además de vecinas del barrio, estudiantes universitarias e integrantes de organizaciones de izquierda.

Los fines de semana haciamos almuerzos entre todos. Juntábamos plata y comida entre todos y a eso le sumábamos las colaboraciones de los vecinos. Estos almuerzos eran fundamentales. Era el día en el que nuestros hijos no tenian que ir a la escuela entonces comíamos todos abi y nos quedábamos a pasar el día y la noche en la fábrica, a veces hasta el otro día, dormíamos abi, en la pecera. La pecera era el lugar de las mijeres. Ahi nos juntábamos nosotras y hablábamos cada una de

53 Vasallo, 2000: 254.

54 Conway, Bourque \& Scott, 1987. 
sus problemas. Yo era una, por ejemplo, de las que no tenía que elegir entre cuál de mis hijos iba a la escuela, porque muchas tenían que elegir o algunas mandaban uno de sus hijos a la mañana y el otro a la tarde para que los dos pudieran usar el mismo par de zapatillas, porque no tenian. Yo tuve la suerte de no tener que pasar por esa situación de elegir cuál de mis hijos iba a la escuela y cuál no.

La pecera era una habitación con grandes ventanas de vidrio ubicada en un sector de la fábrica que las mujeres habían adoptado como propio. Allí no sólo se ponían a la luz las situaciones particulares de cada una de ellas, mate de por medio, se iban tejiendo y reforzando lo que Kaplan denomina redes de relaciones femeninas, se hablaba de política, sobre las negociaciones y se planificaban los eventos que se realizarían para recaudar fondos y visibilizar el conflicto cervecero además de las acciones que llevarían a cabo durante las manifestaciones. Adriana, cuenta que algunas de las mujeres si tenían trayectoria en la militancia, pero muchas como ella no, y que la toma le había dado compañeras con experiencia política y eran ellas quienes la guiaban en ciertas situaciones.

para mi era nuevo todo eso, yo conocía de marchas, pero otro tipo de marchas, por ejemplo, las que se hacian durante el gobierno de Alfonsin, que iba con mi marido $y$ dos de mis hijas muy chiquititas, pero nunca una tan personal. A partir del conflicto, empecé a marchar con mi marido, con mis hijas y con mis hijos. Asi que abi nos guiaban otras mujeres que sabian, que tenian experiencias más profundas. Compañeras y también chicas que venían de la universidad

Fue en estos días en los que las mujeres encontraron en la protesta laboral de sus familiares varones una oportunidad para ocupar el espacio público y hacer política en las calles, organizaron y realizaron asambleas, tomaron decisiones, marcharon a la cabeza de las columnas, hicieron peñas, recaudaron fondos. La entrevistada recuerda que, por aquel entonces, había quienes consideraban que el papel que desempeñaron las "mujeres cerveceras", era notable.

\section{Luces y sombras, conclusiones y aperturas}

Históricamente las mujeres han sido actores fundamentales en las protestas teniendo suma importancia en la historia reciente, principalmente la que tiene lugar dentro de 
los límites de nuestro país desde las últimas décadas del siglo pasado y las primeras del presente. En la misma línea, se considera que el género tanto como la situación económico-social, debe ser vislumbrado como constituyente central de las múltiples aristas que arman las experiencias humanas.

La experiencia de las mujeres en el conflicto de la Cervecería Córdoba, que aunque no es independiente de la de los varones, debe ser valorada como una historia propia y eso es lo que se ha intentado visibilizar en el desarrollo de este trabajo, siguiendo por un camino que intentó responder preguntas que giraron en torno a la importancia de las mujeres durante el periodo de la aplicabilidad de las políticas neoliberales en los noventa, los espacios que ocuparon y cómo y por qué se apropiaron de ellos. Con estos interrogantes como guía, surgieron preguntas más específicas que giraron en torno al papel que jugaron las mujeres en el conflicto cervecero; cómo se definen ellas mismas y cómo definen sus acciones; qué acciones diseñaron y por qué, cuál es la relación que se establece entre lo público y lo privado y cuáles son sus límites, si es que los hay.

Los factores que ayudan a explicar la participación y movilización de las mujeres, permiten observar cómo se entremezclan acciones vinculadas con la extensión de sus roles de cuidadoras en el espacio doméstico con otras vinculadas a su práctica política pública. Si bien se sostiene que con distintas experiencias de participación política y pertenecientes a diferentes clases sociales, las mujeres cerveceras no solamente jaquearon su posicionamiento en la esfera de la domesticidad, sino que también enfrentaron las normativas que demarcaban la ocupación de los espacios públicos, haciendo propia la lucha, adquiriendo un papel imprescindible antes, durante y después del conflicto, este trabajo deja pendientes aún algunas sombras que abren muchos interrogantes, nuevas inquietudes y nuevos desafíos que buscan conocer lo que estas acciones expresaban o intentaban expresar, desde su individualidad pero también entendidas en su conjunto; preguntarse por cómo se perciben, definen, comprenden y describen esas acciones, establecer con más profundidad cuál fue el lugar de la militancia y cómo fueron esos lazos de solidaridad creados entre las mujeres que estuvieron presentes durante los ciento cinco días de toma. Preguntas que encontrarán respuestas a lo largo del proceso de investigación que tiene como fuente principal las voces de las mujeres cerveceras, protagonistas que cuentan en primera persona cómo 
resistieron al modelo neoliberal en los noventa. 


\section{FUENTES}

Diarios

La Voz del Interior, mayo a agosto de 1998.

La Nación, julio de 1998.

\section{Entrevistas}

Pedro, entrevista realizada por Fatima Boccetti, 14 de agosto de 2018.

Adriana, entrevista realizada por Fatima Boccetti, 14 de septiembre de 2018.

Daniel, 9 de agosto de 2018. Recuperado de http://comunismorevolucionario.org/crpmlm Lcerveceria-cordoba-105-dias-de-toma-quemarcaron-un-camino/ [Consulta: 17 de junio de 2021]

Dante, 9 de agosto de 2018. Recuperado de http://comunismorevolucionario.org/ crpmlm Lerveceria-cordoba-105-dias-de-toma-quemarcaron-un-camino/ [Consulta: 17 de junio de 2021]

\section{Documentos}

Pliego de condiciones generales (incompleto), $\mathrm{s} / \mathrm{f}$. Colección personal Pedro, ex trabajador de la Cervecería Córdoba

Panfleto, s/f. Colección personal Pedro, ex trabajador de la Cervecería Córdoba

Leyes

Ley Nacional N²3.696, Reforma del Estado, Argentina, 1989.

Ley Nacional N²3.697, Ley de emergencia económica, Argentina, 1989.

Ley Nacional $\mathrm{N}^{\circ}$ 23.938, Convertibilidad del Austral, Argentina, 1991.

Ley Nacional No 24.522, Concursos y quiebras, Argentina, 1995.

Ley Provincial No 8482, Córdoba, Argentina, 1995.

\section{BIBLIOGRAFÍA}

Alonso, A. 2012, "Repertório, segundo Charles Tilly: História de um conceito" en Sociol. Anthropol, Vol. 2, Núm. 3, pp.21 a 41

Andújar, A. 2007, "Pariendo resistencias: las piqueteras. Cutral Co y Plaza Huincul, 1996" en Bravo, M. C. Gil Lozano, F. \& Pita, V. (Comps.) Historia de luchas, resistencias $y$ representaciones. Mujeres en la Argentina, Siglos xix y $x x$, EDUNT, Tucumán.

Arriaga A, Almada J, Carin G, Gleser R, Puttini M \& Valdemarca L. 2018, "Córdoba entre la reconstrucción democrática y la crisis del 2001" en Ceballos A. Navarro C. \& Philp, M. (Coords.) Itinerarios, recorridos por la Historia de Córdoba. Editorial de la UNC/ Ministerio de Educación, Córdoba.

Barrancos, D. 2007, Mujeres en la sociedad argentina. Una bistoria de cinco siglos, Sudamericana, Buenos Aires.

Conway, J. Bourque \& Scott, J. 1987, “El concepto de género" en Lamas M. (Comp.) El género. La construcción cultural de la diferencia sexual. Grupo Editorial Miguel Ángel Purrua, México.

Gordillo, M. y otros, 2012, La protesta frente a las reformas neoliberales en la Córdoba de fin de siglo, Ferreyra Editores, Córdoba.

Kaplan, T. 1990, "Conciencia femenina y acción colectiva: El caso de Barcelona, 1910 1918” en: Amelang, J \& Nash, M. (Comps.) Historia y género, las mujeres en la Europa moderna y contemporánea, Alfons el Magnanim, Valencia pp. 267 a 296.

Ledesma J. \& Montes, D. 1999, La toma de la Cervecería Córdoba, 105 días que marcaron un camino, Ágora, Buenos Aires.

Lipovetsky, G. 1999, La tercera mujer, Anagrama, Barcelona.

Medina, L. \& Franco, M. 2011, “La protesta territorial en Córdoba entre el auge y la crisis neoliberal" en VI Jornadas de Jóvenes Investigadores del Instituto de Investigaciones Gino Germani, Buenos Aires.

Melucci A. 1999, Acción colectiva, vida cotidiana y democracia, El Colegio de México, México.

Ortale, M. 2015, "Algunas cuestiones de género: trabajo, pobreza y políticas sociales” en Eguía, A. Ortale, M. \& Piovani J. (Comps.) Género, trabajo y politicas sociales, CLACSO, Ciudad Autónoma de Buenos Aires.

Pasquali L. 2013, "Recordar y contar desde el género. Reflexiones sobre los relatos de mujeres/Remember and tell from the genre. Reflections on women's stories" en Revista Izquierdas, Núm. 17, pp. 170 a 191.

Palermo, S. 2011, “Género y ciudadanía política: algunos apuntes en la agenda de 
investigación" en Polbis, año 4, Número 7, pp. 46 a 54.

Palermo, V. \& Novaro, M. 1996, Politica y poder en el gobierno de Menem, Norma/FLACSO, Buenos Aires.

Pateman, C. 1995, El contrato sexual, Anthrophos, Barcelona.

Pateman, C. 1996 Críticas feministas a la dicotomía público/privado, Paidós, Barcelona.

Ramos Ávila, I. 2004, "Mujeres Piqueteras. La reinvención de la política desde abajo" en Revista Toposy Tropos, Núm. 1.

Rodríguez, M. 2007, "El régimen de la insolvencia internacional en el derecho de fuente interna argentino" en Revista Cientifica de UCES. Vol. XI, Núm. 2.

Scott, J. 1990, Dominations and the Arts of Resistance. Hidden Transcripts, Yale University, Londres.

Scoot, J. 2011, Género e Historia, Fondo de Cultura Económica, México.

Svampa, M. 2005, La sociedad excluyente. La Argentina bajo el signo del neoliberalismo, Taurus, Buenos Aires.

Svampa, M. 2004, "Las organizaciones piqueteras: actualización, balance y reflexiones (2002-2004)" en Svampa, M. \& Pereyra, S. Entre la ruta y el barrio. La experiencia de las organizaciones piqueteras, Biblos, Buenos Aires.

Schuster, F. y otros 2006, Documento de trabajo $N^{\circ}$ 48. Transformaciones de la protesta social en Argentina: 1989- 2003, GEPSAC, Instituto Gino Germani, Buenos Aires.

Vasallo A. 2000, "Entre el conflicto y la negociación. Los feminismos argentinos en los inicios del Consejo Nacional de Mujeres, 19001910” en Gil Lozano, F. Pita, V. \& Ini, M. (Dirs.). Historia de las mujeres en la Argentina. Siglo XX. Tomo 2, Taurus, Buenos Aires, pp. 197 a 221. 